\title{
Dealing with the difficult patient
}

\author{
Sam Smith
}

\begin{abstract}
Summary
Dealing with difficult patients can represent a significant burden in the life of doctors. It is more productive, however, to view this burden as a product of the interaction between doctor and patient, for which both have a responsibility, rather than attributing any problems encountered to shortcomings of the patient alone. There is a significant risk in such situations of potentially harmful over-medicalisation. It behoves doctors, therefore, to try to prevent such problems becoming established, or make some attempt to rectify matters if they have already become so. Much is known about the factors that contribute to successful and unsuccessful clinical transactions. The awareness of what doctors bring both as professionals and as individual people to this interaction, will count as much as the practical clinical efforts made towards helping patients.
\end{abstract}

Keywords: difficult patients, communication skills

Demographic characteristics of difficult patients

- older

- more often divorced or widowed

- more often female

- attend more frequently

- more acute problems

- more chronic problems

- more medications

- more X-rays, blood tests and referrals

- have fat folders

- no less provider continuity

Box 1

Health Centre, Lower Robin Hood Lane, Helsby, Warrington WA6 0BW, UK

S Smith

Accepted 1 June 1995
It is said that the first step doctors must take in managing difficult patients is to accept their own negative feelings towards them. ${ }^{1,2}$ Otherwise, in the effort to escape them, needless referrals and unnecessary investigations may be made or ordered. Patients described as difficult by their doctors have been shown to attend more frequently with acute and chronic problems, to be prescribed more medication, have more investigations ordered for them, and to be referred more often for a second opinion..$^{3,4}$ The fat folders of such patients ${ }^{5}$ testify to the amount of medical work generated, and many attempts have been made to define the characteristics of so-called problem patients. ${ }^{4,6-8}$ It is increasingly recognised, however, that this extra and often clinically unnecessary work is a product of the doctor-patient relationship, for which both parties have a responsibility. ${ }^{2,9-12}$ Indeed, the outcome of consultations with patients in general, depends on demonstrable aspects of the behaviour of both doctors and patients. This is true both in terms of clinical parameters, ${ }^{13}$ and in terms of patient compliance and satisfaction. ${ }^{14-16}$

Rather than the characteristics of problem patients alone, therefore, what demands attention is how characteristics of both patient and doctor shape, and are shaped by, the doctor-patient interaction. Thus, an approach which explores the difficulties of the clinical transaction itself, rather than the supposed failings of the problem patient, is likely to prove more fruitful. ${ }^{17}$ Social forces which influence the attitudes and expectations of both doctors and patients, must also be given consideration. These influences are not necessarily harmonious, for whilst there is often a productive reciprocity of doctor and patient roles, this cannot be assumed. ${ }^{18}$ As well as conforming to the pressures of social norms, doctors and patients develop as unique individuals, and bring personal and idiosyncratic attributes to the clinical transaction. Aspects of personality can dramatically effect the process and outcome of the clinical transaction. ${ }^{17,19}$

These themes will be explored in this paper with the aim of re-framing the problem of the difficult patient, and thereby going some way towards dispelling it. Any improvement in the quality and outcome of clinical transactions with such patients might be judged by the evaporation of negative feelings, and fewer unnecessarily fat folders.

\section{Characteristics of problem patients}

Historically, strict medical criteria for identifying problem patients have not been uniformly employed. ${ }^{3}$ They are more often women, and complain of ill-defined somatic symptoms which fluctuate over time and seem to have no organic basis. ${ }^{2}$ Whilst consuming disproportionate amounts of healthcare they appear to gain little benefit from it. They are capable of kindling aversion, fear, despair or even downright malice in their doctors. ${ }^{6}$ Such powerful feelings fuel the process by which doctors attach to these patients such unflattering epithets as heartsink, ${ }^{7}$ black-holes, ${ }^{8}$ crocks or turkeys, ${ }^{12}$ and many more besides. Stereotyping, however, may prejudice the range of responses brought to bear on a problem, especially if the stereotype is a stigmatising label. Problem patients are often said to display abnormal illness behaviour, somatize, or to suffer from a personality disorder.

\section{ABNORMAL ILLNESS BEHAVIOUR}

According to the biomedical model, symptoms are the subjectively experienced consequences of physical or psychiatric disease. Furthermore, in Western medical epistemology, it is held that there is a correspondence and association between changes in the body, and states of mind and behaviour. ${ }^{20}$ Symptoms, therefore, ought only to exist in the presence of disease, and should provoke the patient to seek appropriate medical help. It has become obvious, however, that people experience and respond to their symptoms in many different ways. To account for this fact, Mechanic developed the concept of illness behaviour. ${ }^{21}$ The concept was extended by Pilowski to encompass the presentation of symptoms in the absence of disease, or out of proportion to the degree of physical pathology. 


\begin{tabular}{|l|}
\hline Personality disorder \\
\hline - often associated with various \\
degrees of subjective distress and \\
with problems in social functioning \\
and performance \\
- care should be taken in applying \\
this term diagnostically \\
- not all problem patients have a \\
diagnosable personality disorder \\
- some doctors may have a \\
diagnosable personality disorder \\
\hline
\end{tabular}

Box 2

\begin{tabular}{|l|}
\hline Doctors' styles \\
\hline - doctors' styles can affect the \\
outcome of clinical transactions \\
- task-oriented styles, where \\
information is exchanged, lead to \\
better compliance \\
- styles including social and \\
emotional exchange lead to greater \\
satisfaction \\
- doctors' styles tend to be fixed \\
problems can arise when the \\
consulting styles of patient and \\
doctor conflict \\
\hline
\end{tabular}

Box 3

\section{Case history 1}

Following her husband's death from a heart attack, Mrs A herself developed chest pains. A diagnosis of angina was made. She became neurotically anxious about her heart and was admitted to hospital several times with chest pain. Myocardial infarction was never confirmed. She frequently consulted her general practitioner, who came to dread her visits, and her treatment was changed many times. Following her last admission, an exercise electrocardiogram was arranged which was completely normal. When told this she was at first disbelieving, then became depressed. As part of the treatment of depression she was able to address her fears and the unresolved grief after losing her husband. Her chest pains did not return.

\section{Comment}

Mrs A became a difficult patient for her general practitioner because of her anxiety, her failure to respond to treatment, and his own doubt about the potentially life-threatening diagnosis. The equivocal outcome of her hospital admissions compounded a process of somatic fixation. This perpetuated Mrs A's psychological defence of denial and avoidance in the face of her husband's death.
Patients who present with trivial or unfounded somatic complaints can, by this account, still find their place within medical rationality if deemed to be displaying abnormal illness behaviour. ${ }^{22} \mathrm{~A}$ short step further, and such modes of presentation can be assigned a psychiatric origin, and thus be firmly reclaimed by the medical model. This doctor/disease-centered endeavour has been increasingly criticised. ${ }^{18}$

\section{SOMATIZATION}

Somatizing patients are defined as those who frequently complain of physical symptoms that either lack demonstrable organic bases or are judged to be grossly in excess of what one would expect on the grounds of objective medical findings. ${ }^{23}$ Such patients are often labelled difficult by their doctors. As a concept, like abnormal illness behaviour, somatization bridges the mind/body and disease/ illness dualism that is so challenged by much of patient behaviour. The determinants of somatization are not entirely clear and may depend on cultural or familial factors. ${ }^{23}$ When compared to patients who present problems in more psychosocial terms (psychologisers), somatizers tend to be less depressed, report lower levels of social dissatisfaction, less social stress and less dependence on relatives. They are more likely to have an unsympathetic attitude towards mental illness and less likely to consult a doctor about psychological symptoms. They are more likely to have received medical in-patient care as an adult before they had consulted their doctor with their current illness. ${ }^{24}$ In spite of these findings, there is a clear link between somatization and psychiatric illness, especially depression, ${ }^{24}$ and patients who present somatically are more likely to be misdiagnosed as having a physical illness by their doctors. ${ }^{25}$ Somatization is often used interchangeably with concepts such as hypochondriasis and hysteria. These latter, however, are often employed pejoratively, rather than as reliable diagnostic terms. It is doubtful whether somatization itself achieves the status of a diagnosis, for it is often observed, even if only transiently, as part of the normal presentation of illness. ${ }^{22}$

\section{PERSONALITY DISORDER}

Those who suffer from disordered personalities, be they patients or doctors, are often difficult to deal with. The definition of personality disorder ${ }^{26}$ is based in part on this very fact. It is a complex subject and only one or two points will be made here. A feature of personality disorder involves the prominent and habitual deployment of rigid mechanisms of psychological defence. Such defences develop to protect the mind against the psychological effects of sustained adverse circumstances during the early development of the personality. ${ }^{17}$ Their effect is to distort a person's perception of themselves and others in ways which interfere significantly with straightforward communication and the capacity to seek and receive help (see below). By no means all problem patients, however, satisfy strict criteria for a diagnosable personality disorder.

\section{Characteristics of doctors}

By virtue of their medical training, together with aspects of their personalities, doctors develop a particular style of relating to patients and their problems. For an individual doctor, this style seems to be remarkably constant from consultation to consultation ${ }^{36}$ and has been typified in numerous ways..$^{14-16,27-29,36}$ One important dimension that distinguishes doctors is how doctor-centred or patient-centred they are. This depends on how far doctors adhere to a strict medical model as opposed to a more psychosocial or counselling approach involving an attempt to see the problem in the patient's own terms. Another observable dimension is the capacity to tolerate uncertainty and the willingness to take risks. ${ }^{29}$ In terms of the patients they treat, doctors characteristically rate as most difficult to help those who: attend frequently; show more emotional distress; have symptoms unexplained by organic disease; have chronic organic disease together with severe psychosocial problems; and those with chronic disease for which medical treatment is ineffective. ${ }^{30}$

It should be remembered that the personal characteristics of an individual doctor can contribute as much to the difficulty of a clinical transaction as those of the patient.

\section{Doctor-patient interaction}

Those aspects of patients and doctors discussed so far obviously fall short of a complete and relevant characterisation. They are important, however, because they contribute to the styles in which patients present and doctors respond to illness (box 3). If styles are not compatible, this may complicate the clinical 
transaction. A medically oriented doctor, for example, might have difficulty dealing with an emotional presentation of psychosocial problems. A patient whose idiom of self expression is primarily somatic, may have difficulty cooperating with a psychosocial enquiry. ${ }^{17}$ Hall has shown that the outcome of the doctor-patient interaction, in terms of patient compliance, is favoured by an informative and task-oriented style. Satisfaction is more related to the amount of socioemotional exchange. ${ }^{15}$ Better health outcomes in terms of physiological measurements and functional capacity result from interactions in which there is: more control by patients; more expression of emotion (positive or negative) by either doctor or patient; and more information sought by patients and given by doctors. ${ }^{13}$ On the other hand, doctor-centred interactions, as Grol has found, are associated with more prescription of symptomatic medication and poorer psychosocial care. ${ }^{27}$ The presentation of somatic symptoms within the context of a rigidly applied medical model can lead to somatic fixation and overmedicalisation. ${ }^{31}$

\section{Public and personal domains}

\section{Public and personal} domains

- the doctor-patient interaction is pursued on two levels

- the public domain encompasses the attitudes, expectations, and responsibilities defined by social roles, including clinical work

- the personal domain encompasses the level of interaction determined by aspects of the individual personalities of doctor and patient

- style is a combination of public and personal influences

- the domains interact

- failures in clinical transactions can become apparent in one domain, but originate in the other

\section{Box 4}

\section{Case history 2}

Dr Z was a committed general practitioner who worked hard on behalf of her patients. Mr B, a young man, attended frequently with vague somatic symptoms and fatigue.

Routine tests were normal and Dr Z concentrated on counselling and medication for depression. Mr B improved initially and seemed grateful, but before long his symptoms returned, and nothing seemed to help. On one occasion he brought back his unfinished medication describing it as useless. Dr $Z$ was surprised at her sudden dislike for this patient, but concealing her irritation she said she would refer $\mathrm{Mr}$ B to a psychiatrist.

\section{Comment}

Mr B's rejection of Dr Z's treatment aroused hostility, which although concealed, may have prompted the decision to refer. This, in turn, may have been experienced by $\mathrm{Mr} \mathrm{B}$ as a rejection. Acknowledging her feelings to herself, Dr Z might more productively have discussed the apparent stalemate they had reached observing, in a spirit of enquiry, the fact that nothing seemed to help.

\section{THE PUBLIC DOMAIN}

Health benefits and expectations, for both patient and doctor, are largely constructed through either formal - as in the case of medical training - or informal social practices. Such practices result in the conventional roles enacted by doctor and patient within the clinical transaction. Each role implies certain attitudes and entails certain responsibilities, such as establishing a diagnosis, prescribing medication, and cooperating and complying with treatment. The clinical tasks of the transaction, including negotiating and agreeing appropriate goals, constitute the public domain of doctor-patient interaction. ${ }^{17}$ As Armstrong has pointed out, there is not always a cosy reciprocity between the roles of doctor and patient, and patients may not present with illnesses which comfortably conform to the medical model. This does not mean, however, that they cannot account for their symptoms in rational terms, even if they are not the terms of medical rationality. ${ }^{18}$ Some effort must be made, therefore, to ensure a shared understanding of problems and explanations. In this respect it should be acknowledged that the performance of the patient role demands a level of psychosocial accomplishment and maturity that some patients do not achieve. Furthermore, any such capacity is likely to be undermined by the effects of illness itself.

\section{THE PERSONAL DOMAIN}

As well as being pursued on the level of the public domain, clinical transactions necessarily involve the interaction of doctor and patient as individual personalities. At this level reactions to the other person are immediate and can fluctuate rapidly. Such reactions may generate emotions reaching awareness, but they may motivate behaviour unconsciously. For example, doctors are, at least to some extent, a self-selecting group pursuing a vocation. Their motivation is likely to lead them to act in the service of patients and thus sustains the straightforward performance of the clinical transaction. At a personal level, however, care may be provided as if it were a gift to the patient. Should the gift of care be rejected or discounted doctors may be open to hurt or disappointment, and may feel less well-disposed towards patients as a consequence.

\section{TRANSFERENCE AND COUNTERTRANSFERENCE}

The circumstances and relationships of early development are inevitably beset by hardship and frustration to some degree. As a result people acquire patterns of psychological defences, and accumulate unresolved emotional conflicts, of which they are mostly unaware. These defences and conflicts remain to be erected or re-enacted in the context of current relationships via processes of transference and countertransference. ${ }^{17}$ In some circumstances, such as when faced by a patient experienced as particularly difficult, it is as if these emotional residues are re-activated. A well-disposed attitude may then be displaced by strong negative feelings, sometimes amounting to hate. ${ }^{6,32-34}$ Such unwelcome emotions may be repressed, but at the risk of finding unconscious expression in punitive, neglectful, or rejecting responses towards patients. Strong positive, especially sexual, feelings can equally distort professional attitudes and behaviour, in different, but no less inappropriate ways.

People who have suffered severe and sustained adversity in early life, perhaps physical or sexual abuse in childhood, are likely to develop extreme and rigid defences as a consequence. Whilst internalising their experience as victims, they may, in an attempt to defend themselves against feelings of powerlessness and helplessness, also have internalised aspects of the powerful abuser. The theme of 


\section{Case history 3}

$\mathrm{Mr} \mathrm{C}$ seemed an aggressive and resentful young man. He had been known to shout at the receptionists and nurses in the hospital clinic he had attended for some time with a chronic illness. During one visit Sister $\mathrm{Y}$, the nurse in charge, took him to task and in the heat of argument told him that he was just like her teenage son. $\mathrm{MrC}$ responded by saying she was just like his mother.

\section{Comment}

It is, of course, appropriate and legitimate to place limits on acceptable behaviour. In this instance emotional conflicts arising in family systems breached the boundary of the professional nurse/patient system. $\mathrm{Mr}$ C's attitude in the clinic was fuelled by the ingrained resentment of his treatment by his parents. Sister Y's reaction was aggravated by ongoing problems with her own son. The interactive effect exacerbated matters leading to Sister Y's confrontation of Mr C. Limits imposed one-sidedly in the heat of an argument are unlikely to succeed. A quieter, more reflective approach might have been more effective, with an attempt to understand the underlying emotional problems. Particular attention should be paid to boundary issues. victim/victimiser can thus come to dominate their relationships with others, including their doctors. When such a patient, with a strong sense of self as a victim, presents to a doctor, the doctor may be drawn unwittingly into enacting the victimiser. The result is a self-fulfilling prophecy in which the dominant experience of the patient's life is repeated. ${ }^{17}$ The feelings generated in such circumstances represent a powerful form of covert communication which if understood, can illuminate the emotional predicament of the patient. ${ }^{6}$ When things go wrong in a clinical transaction, therefore, it is not always a result of misdiagnosis or inadequate medication, or the awkwardness or stupidity of the difficult patient. It may also be a reflection of the acting-out of personal and interpersonal conflicts by doctor, patient, or both.

\section{Systems}

The theory of systems is widely applicable, and adopting a systemic perspective can help to re-frame the problem of difficult patients. Problems which derive from applying the medical model too narrowly can be avoided by adopting a biopsychosocial model. ${ }^{35}$ According to such a model the human organism constitutes but one level in a natural hierarchy of systems ranging from the atomic to the cultural. These systems are linked by flows of information in the hierarchy which are different in nature at different levels; molecular at the level of the synapse, symbolic at the level of human language. Regulatory, homeostatic, and adaptive processes operate within and between systems. A particular disease may exert its primary effect at one level, but through the transmission and feedback of information, also affect other levels in the hierarchy. Such a perspective inclines towards interpretation of illness and disease in multifactorial, holistic and patient-centered terms, rather than unitary causes and effects.

The clinical transaction involving an individual doctor and patient, can also be viewed as a system within the hierarchy of systems of healthcare. As individuals doctor and patient belong simultaneously to overlapping systems such as families. Events in one system influence, and are influenced by, events in other systems. For example, the decision to limit costs taken at one level of the healthcare hierarchy can effect the interaction of patient and doctor at the level of the clinical transaction. It is well to remember, when in the grip of a difficult encounter with a patient, that contributions to that difficulty may emanate from conflicts belonging more properly to another related system.

\section{Dealing with the difficult patient}

PREVENTIVE MEASURES: MONITORING THE CLINICAL TRANSACTION

Becoming aware of and accepting negative feelings towards a patient can enable the doctor to avoid reacting in counterproductive ways. As discussed, negative feelings may be roused in doctors when: patients present illnesses that do not fit the medical model; medical and lay explanations of disease conflict; patients fail to comply with treatments or fail to respond to them; or when in some other respect patients fail to play the expected patient role. Patients may be unhappy with their doctors if they: do not listen; do not provide information; are incompetent; or do not engage emotionally with them in an appropriate way. Factors such as these are open to scrutiny because they lie predominantly within the public domain of the clinical transaction, and efforts can be made to remedy them.

More subtle influences on the doctor-patient interaction can be difficult to guard against. People unconsciously perceive and react to others on the basis of past important relationships and events, to a greater or lesser degree, and may project a role for them that may be grossly distorted and inaccurate. Negative feelings may be the result of being cast in a role that feels uncomfortable. Such a role may be incompatible with the view that doctors or patients have of themselves, or with an appropriate, professional doctor-patient relationship. For instance, patients sometimes over-idealise their doctors such that they can do no wrong. Alternatively, they may manifestly mistrust anything the doctor has to offer. Via similar psychological mechanisms doctors may fail to respect their patients sufficiently. Factors such as these lie within the personal domain of doctor-patient interaction and are consequently often more obvious to others than to the participants themselves. Discussion with colleagues can be extremely helpful, especially if based on consultations which have been videotaped. Skill in monitoring the transaction on the personal level involves becoming aware of any out-of-place feelings, attitudes or behaviour that arise. These may represent the earliest clues that all may not be well. Norton and Smith emphasise the importance of recognising how public and personal domains interact. Even though an unsatisfactory outcome of a clinical transaction may obviously lie in 


\section{Reparative measures}

- review the notes

- review and re-assess doctors' and patients' feelings and behaviour, for evidence of unwanted transference and countertransference effects (consider using videotapes)

- review the possibility of conflicting influences from related systems

- agree, list and prioritize problems

- set realistic limits on expectations of the delivery and outcome of care

- consider treatment contracts

- involve other family members

- discuss with partners and other members of practice staff

\section{Box 5}

1 Cohen J. Diagnosis and management of problem patients in general practice. $\mathcal{F} R$ Coll Gen Pract 1987; 37: 51 .

2 Corney RH, Strathdee G, King M, Williams P Sharp D, Pelosi AJ. Managing the difficult patient: practical suggestions from a study day. $R$ Coll Gen Pract 1988; 38: 349-52.

3 McGaghie WC, Whitenack RH. A scale of measurement of the problem patient labelling

process. $\mathcal{F}$ Nerv Ment Dis 1982; 170: 598-604.

John C, Schwenk TL, Roi LD, Cohen M Medical care and the demographic characteristics of 'd

5 Schrire S. Frequent attenders - a review. Fam Pract 1986; 3: 272-5.

6 Groves JE. Taking care of the hateful patient. $N$ Engl f Med 1978; 298: 883-5.

7 O'Dowd TC. Five years of heartsink patients in general practice. $B M \mathcal{F} 1988 ; 297: 528-30$.

8 Gerrard TJ, Riddell JD. Difficult patients: black holes and secrets. $B M \mathcal{F}$ 1988; 297: 530-2.

9 Anstett R. The difficult patient and the physician-patient relationship. $\mathcal{f}$ Fam Pract 1980; 11: $281-6$.

10 Baughan DM, Revicki D, Nieman LZ. Management of problem patients with multiple chronic diseases. f Fam Pract 1983; 17: 233-9.

11 Crutcher JE, Bass MJ. The difficult patient and Crutcher JE, Bass MJ. The difficult patient and
the troubled physician. $\mathcal{F}$ Fam Pract 1980; 11: the trou

12 Kuch JH, Schuman SS, Curry HB. The problem patient and the problem doctor or do quacks make crocks? $f$ Fam Pract 1977; 5: 647-53

13 Horder J, Moore GT. The consultation and health outcomes. Br $\mathfrak{f}$ Gen Pract 1990; 40 $442-3$.

the public domain, such as a failure to comply with treatment, the cause, such as a failure of trust, may lie in the personal domain. They describe the use of a transaction window as an aid in deciding where, how, and why clinical transactions have become complicated. ${ }^{17}$

\section{REPARATIVE MEASURES}

Some patients, despite the most sincere and committed efforts of their doctors, seem to be beyond the reach of medical help, and yet persist in seeking it. In a few cases, some authors conclude that time is more profitably spent with other patients. ${ }^{7,8}$ In many cases more positive action can be taken (see box 5 )..$^{2,7,8,17}$ It may be worthwhile to conduct a thorough psychosocial enquiry, involving other professionals where appropriate. Sharing problems with colleagues can both lighten the burden and be a source of valuable insight into the stalemate that so often exists. Other members of the primary healthcare team and the practice staff should be involved in order to develop a consistent approach towards such patients. These measures compliment the monitoring of clinical transactions described above.

14 Hall JA, Roter DL, Katz NR. Task versus socioemotional behaviour in physicians. Med Care 1987; 25: 399-412.

15 Hall JA, Roter DL, Katz NR. Meta-analysis of correlates of provider behaviour in medical encounters. Med Care 1988; 26: 657-75.

16 Savage R, Armstrong D. Effect of a general practitioner's style on patient's satisfaction. practitioner's style on

17 Norton K, Smith S. Problems with patients: managing complicated transactions. Cambridge: managing complicated transactions.

18 Armstrong D. Illness behaviour revisited. In: Lacey JH, Sturgeon DA, eds. Proceedings of the 15th European Conference on Psychosomati Research. London: John Libby \& Co Ltd, 1986, pp 115-9.

19 Balint M. The doctor, his patient, and the illness. New York: International Universities Press, 1957.

20 Fabrega $\mathrm{H}$. The concept of somatization as a cultural and historical product of Western medicine. Psychosom Med 1990; 52: 653-72.

21 Mechanic $D$. The concept of illness behaviour. $f$ Chronic Dis 1962; 15: 189-94.

22 Pilowski I. Abnormal illness behaviour. $\mathrm{Br} f$ Med Psychol 1969; 42: 347-51.

23 Lipowski ZJ. Somatization: the concept and its clinical application. Am $\mathcal{F}$ Psychiatry 1988; 145: 1358-68.

24 Bridges K, Goldberg D, Evans B, Sharpe T. Determinants of somatization in primary care. Psychol Med 1991; 21: 473-83.

25 Katon W, Kleinman A, Rosen G. Depression and somatisation, a review. $\mathrm{Am} \mathcal{F} \mathrm{Med} 1982 ; 72$ $127-35$.
26 World Health Organization. ICD-10 Classification of mental and behavioural disorders. Clinical descriptions and diagnostic guidelines. Geneva, WHO, 1992.

27 Grol R, de Maeseneer J, Whitfield M, Mokkink $\mathrm{H}$. Disease-centred versus patient-centred attitudes: comparison of general practitioners in Britain, Belgium and The Netherlands. Fam Britain, Belgium and

28 Bucks RS, Williams A, Whitfield MJ, Routh DA. Towards a typology of general practitioners' attitudes in general practice. Soc Sci Med 1990; 30: 537-47.

29 Calnan M. Images of general practice: the perceptions of the doctor. Soc Sci Med 1988; 27: 579-86.

30 Sharpe M, Mayou R, Seagroatt V et al. Why do doctors find some patients difficult to help? $Q \mathcal{F}$ Med 1994; 87: 187-93.

31 Grol R. To heal or to harm: the prevention of somatic fixation in general practice. $\mathrm{R}$ Coll Gen Pract Monogr, 1981.

32 Winnicott DW. Hate in the countertransference. In: Through paediatrics to psycho-analysis. In: Through paediatrics to psycho-analysis. Psycho-Analysis, 1987.

33 Prodgers A. On hating the patient. $\mathrm{Br} f$ Psychother 1991; 8: 144-54.

34 Adler G. Helplessness in the helpers. $\mathrm{Br} F \mathrm{Med}$ Psychol 1972; 45: 315-26.

35 Engel GL. A unified concept of health and disease. Perspect Biol Med 1960; 3: 459-85.

36 Byrne PS, Long BEL. Doctors talking to patients. R Coll Gen Pract Monogr, 1984. 